\title{
Loess caves of Austria - a preview
}

Pavuza, R. ${ }^{1}$ and Plan, L. ${ }^{1}$

(1) Karst and Cave Working Group, Museum of Natural History Vienna, Austria

https://doi.org/10.17979/cadlaxe.2013.37.0.3583

\begin{abstract}
Loess caves account for a negligible amount of Austria's caves only - despite the fact that the areas covered by loess and loess-loam comprise several thousand square kilometres. Loess can be found in the northern and eastern foreland of the Alpine Mountain Range as well as in the Styrian Basin south of the Alps. Only a handful of caves have been mapped so far, concentrated at a few spots. This eye-catching fact documents a certain lack of exploration rather than a general lack of loess caves. According to Striebel (2005) and others most loess caves are formed by piping and gully erosion, initiated by inhomogeneities like disintegrating roots and animal burrows where the infiltrating water causes fast-growing pipe structures, subsequently enlarging to caves that can be entered by cavers.

The rate of cave evolution is tremendous. In several cases - so far investigated - the earliest onset of cave formation lies within the early 20th Century. This can be dated as the required gradient was man-made at that time. On the other hand distinctive alterations of the caves took place within 30 years. This can be documented strikingly by comparing old and new cave maps. The crucial points - from a quantitative point of view - for the formation of loess caves are still under fundamental discussion as there are severe differences in local climatic parameters - some of the areas belong to the driest in Austria - lithologies, gradients and human interventions. Furthermore, the role of dissolution of calcitic components enhancing the subsequent erosion remains ambiguous.
\end{abstract}

Key words: Loess caves; Alpine Mountain Range; Styrian Basin; piping; gully erosion. 


\section{GEOLOGICAL FRAMEWORK}

Loess - a perigalcial aeolian sediment including loess-loam - comprises a large area at the forefront of the Alpine Mountain Range between Salzburg and Vienna as well as the northern part of the Vienna Basin and parts of the Styrian and Pannonian Basin in southeastern Austria.

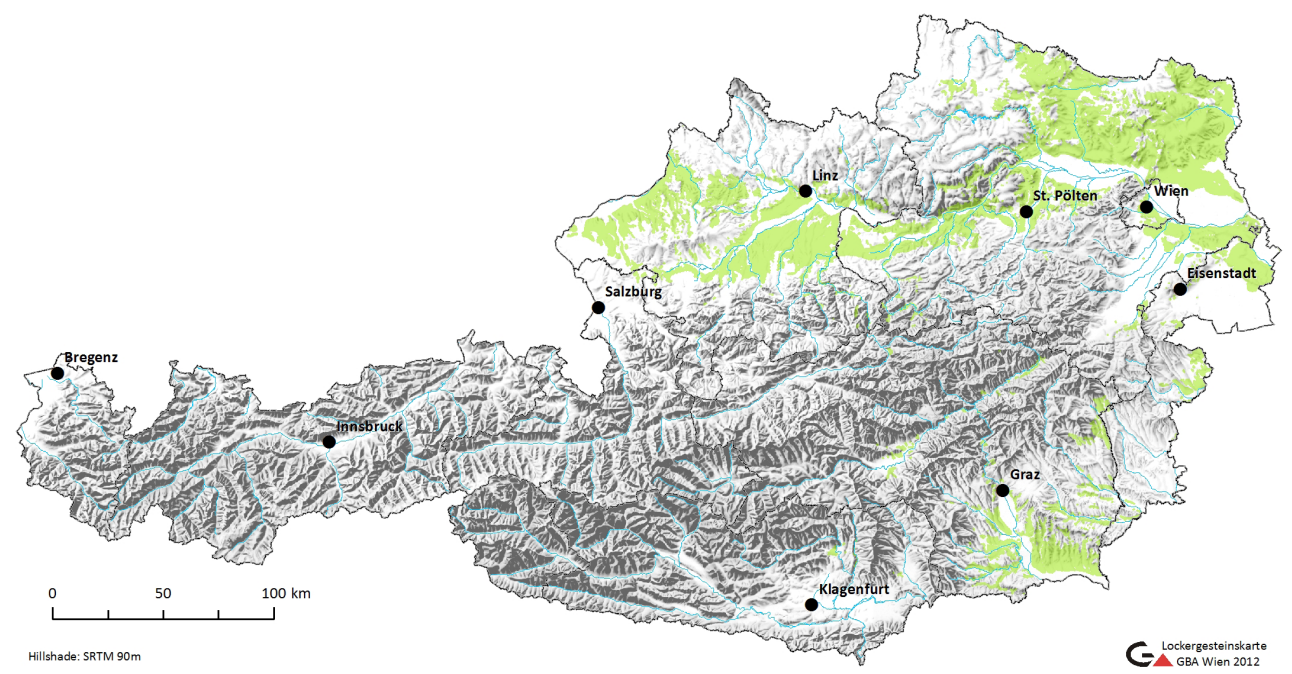

Fig.1. Distribution of the areas with loess in Austria (map supplied by Geological Service of Austria).

This distribution-map does not take account of the relief, being crucial for the formation of caves as it turned out during our investigations and preceding works of other authors on this topic (Striebel, 2006 and Lukič et al., 2009). Furthermore the areas with loamy loess - included in the distribution map - may not favour the formation of caves. But this assumption has not been studied yet.

\section{FORMATION - DEVELOPMENT - DESTRUCTION}

Due to gradients caused by fluvial erosion or man-made (construction of roads, terraces...), the erosional force of infiltrating waters is increased within the loess sequence. Erosion might happen along roots or tubes formed by the deterioration of roots, animal burrows or vertical fractures that formed due to slope instabilities or even neotectonics. Tiny proto-caves act as collectors and a focused selective erosion ultimately leads to accessible caves. This can be regarded - if so wished - as a true "pseudokarst" cave genesis, as a similar hydrogeological selection - but mainly focussing on chemical dissolution - happens in the course of karst-caveformation.

As far as our examples are concerned, the vertical evolution predominates, but nevertheless some sub-horizontal, canyonlike passages can be observed too. Those might form 
along the top layers of more clayey sequences of the sediment. Likewise, less permeable layers on top of the loess are important for an increased stability of the cave.

By all means, the life expectancy of the cave is limited due to the lateral erosion of the slope at the side respectively beneath beside the cave. Lukič et al. (2009) summarized the schematic evolution of loess caves in the Vojvodina (Serbia) which can be used as a general model of cave formation in loess sequences.
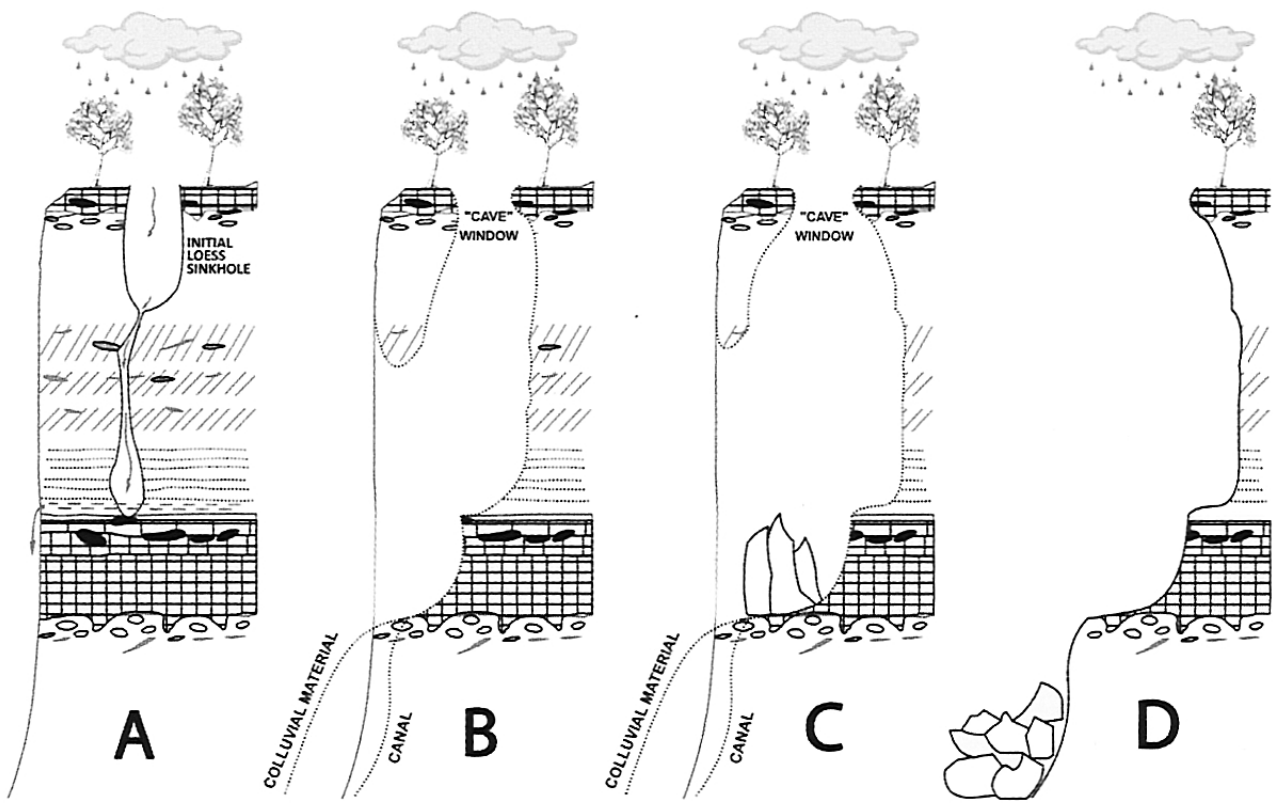

Fig. 2. Evolution of loess caves (from Lukič et al., 2009).

\section{EXAMPLES}

\section{Untermarkersdorf (Lower Austria)}

This location - situated in a winegrowing area near the boundary of the Czech Republic - has been overformed at the beginning of the 20th Century by construction of terraces in order to make wine harvesting somewhat easier. This implied a higher gradient of infiltrating waters and favoured the formation of proto-caves and subsequently caves sensu stricto. Today there is a small system with two vertical entrances, a steep descending cave passage and a 5-m-shaft that has been partly eroded and therefore opened laterally. The cave - so far not yet mapped - might have an overall length of about 20 meters. Several other - sometimes artificially overformed - caves and proto-caves can be observed too. A simple device has been mounted to study the speed of cave passage alterations recently, 


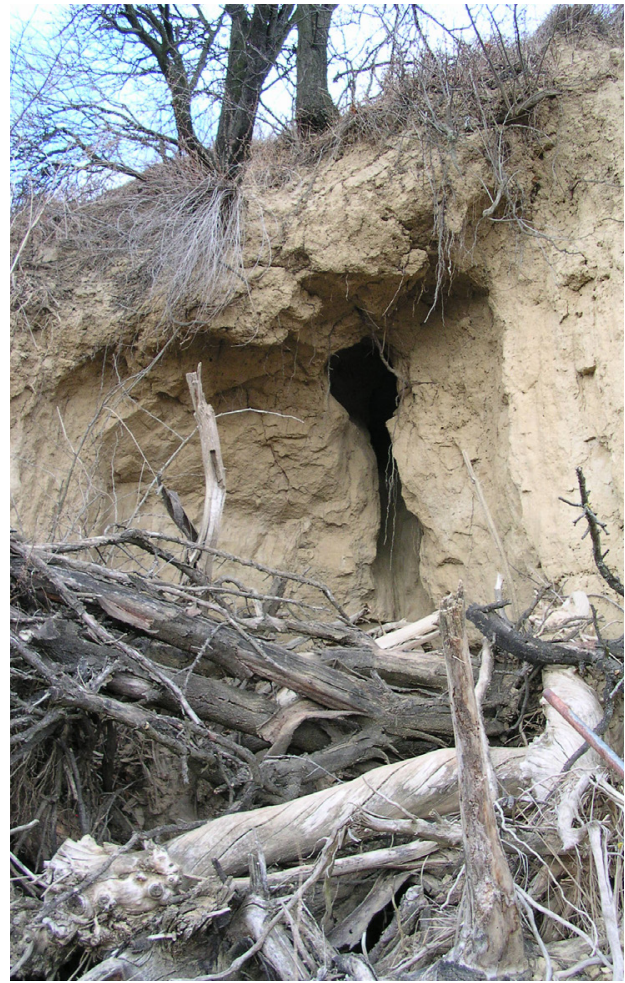

Fig. 3. Middle [subhorizontal] passage of the loess cave in Untermarkersdorf (Lower Austria) behind the wooden barriere a 5-m shaft continues downwards (photo February 2012).

\section{Ruppersthal (Lower Austria)}

Due to major road constructions, resulting in a roadcut up to 10 meters high, and subsequently excavated and marked wine cellars a "minimum age" of the caves - 1932 - can be defined. The overall age may not be substantially higher, but this has to be proofed by other historical data yet. Some of the caves are already in the late stage of

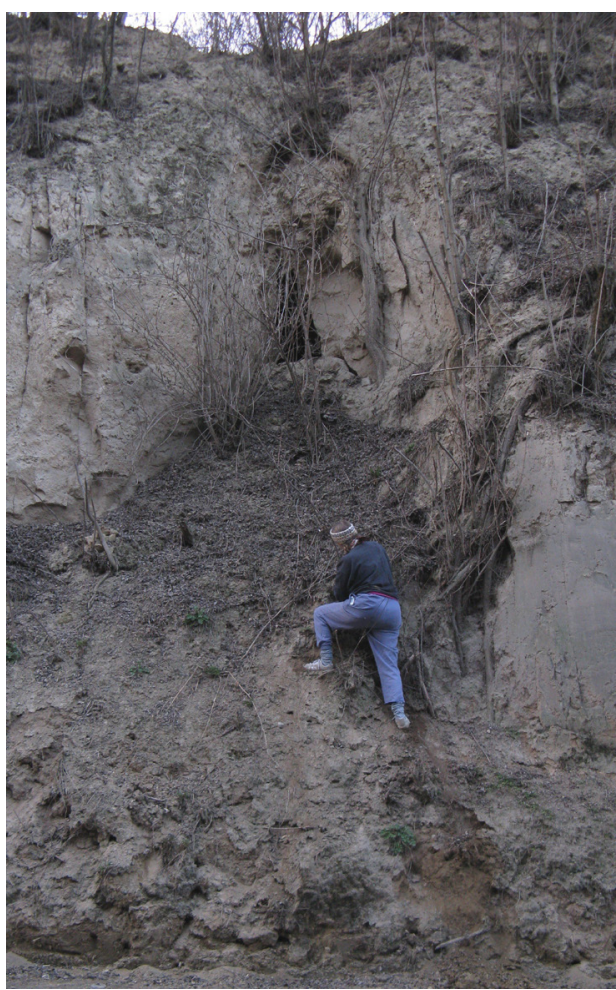

Fig.4. Lower entrance of the loess cave of Ruppersthal (Lower Austria) $\sim 2 \mathrm{~m}$ above the ascending caver (photo March 2012).

their evolution - with vertical shafts already opened by lateral erosion while another shows both vertical as well as subhorizontal passages (Fig.4). Unfortunately, the entrance point of the cave at the surface has been filled with rubbish and is not passable anymore. The lithological difference between the most sandy loess (with the cave in it) and the basal, less permeable layers is obvious (Fig. 5). 


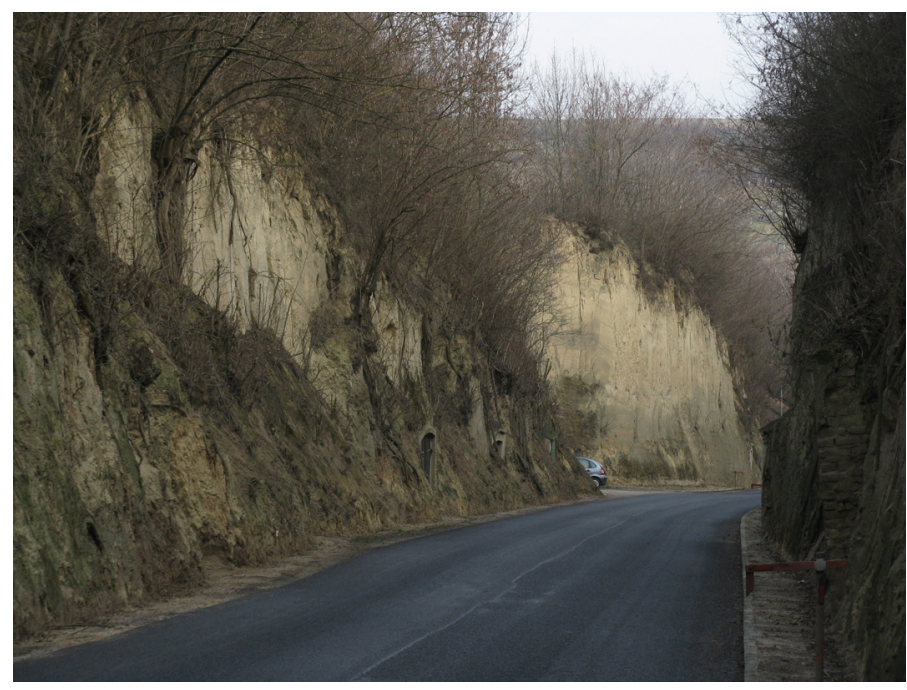

Fig. 5. Roadcut near Ruppersthal (Lower Austria). Caves are located within the upper, brighter loess section (photo January 2012).

\section{Engelmannsbrunn (Lower Austria)}

This example can be regarded as the best documented of its kind in Austria so far as the caves have been mapped twice - 1980 and 2005. The rapid evolution of the loess cave is obvious (Fig.6), showing the rapid deterioration of the passages.

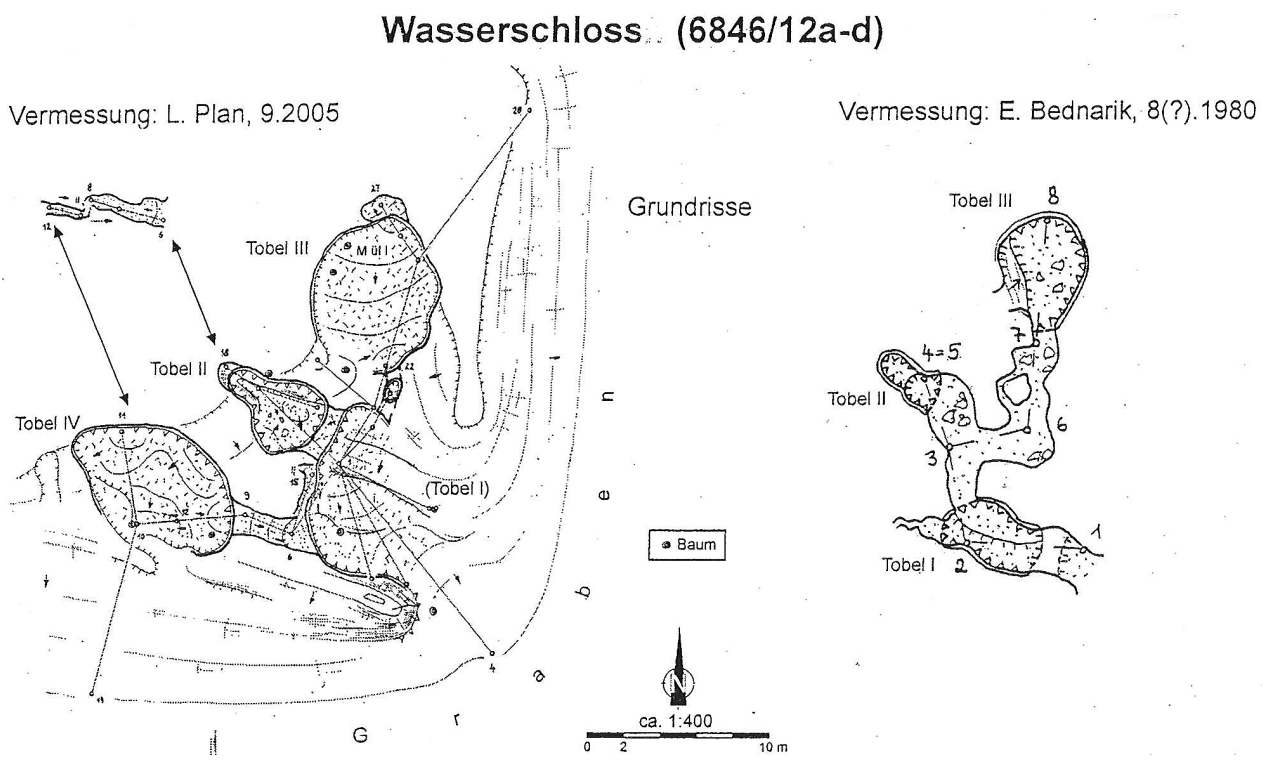

Fig. 6. Cave mapping (1980/2005) of the "Wasserschloss"-Cave near Engelmannsbrunn (Lower Austria). 
The extensive, predominantly natural gulley enables to observe all different stages of loess cave evolution from root-channel enlargement to collapse (Fig. 7-10).

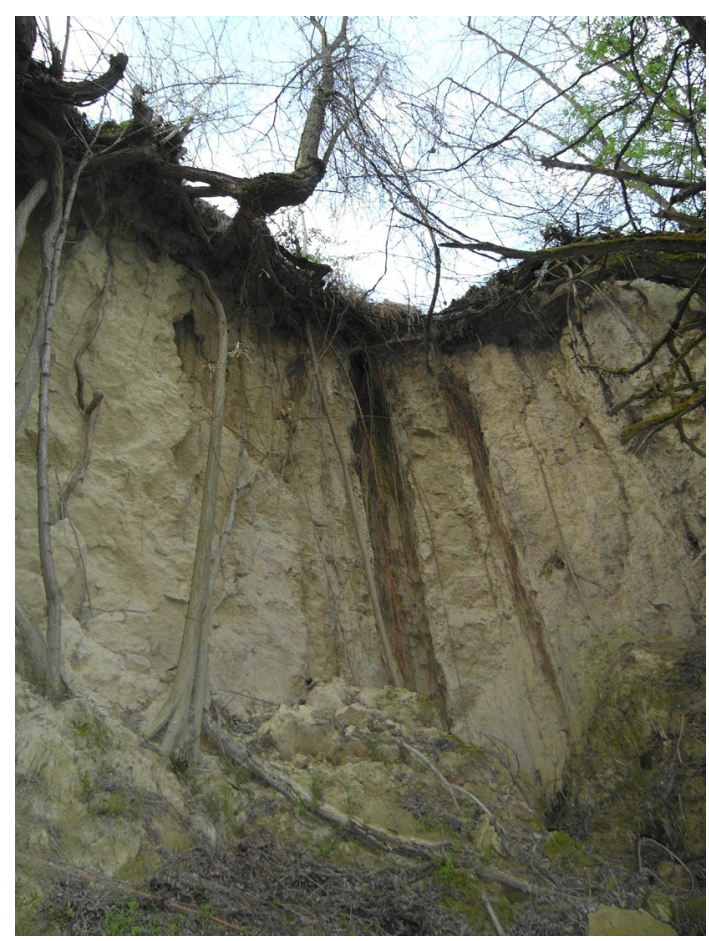

Fig. 7. Enlargement of root channels in the gulley near Engelmannsbrunn (Lower Austria, photo June 2011).

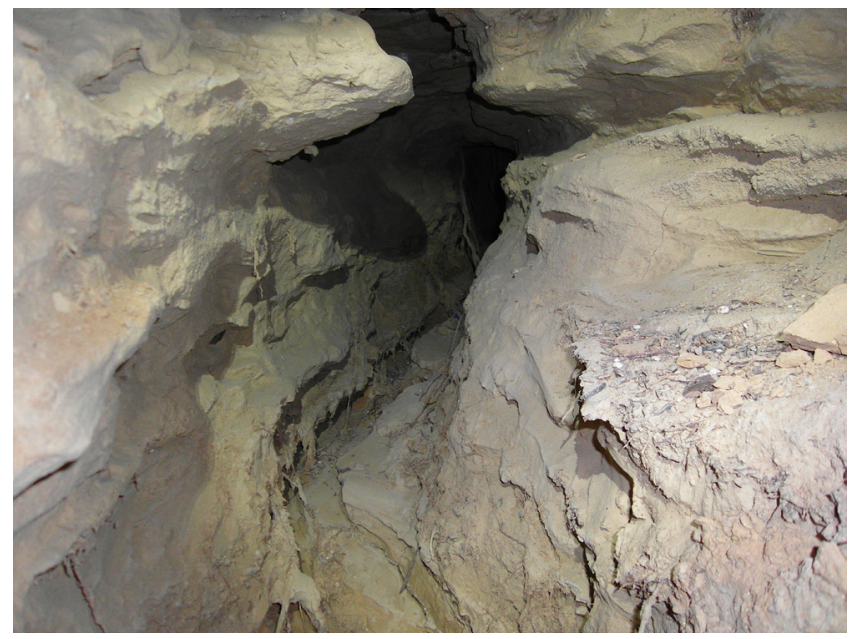

Fig. 8. Sub-horizontal section of a loess cave near Engelmannsbrunn (Lower Austria, photo June 2011). 


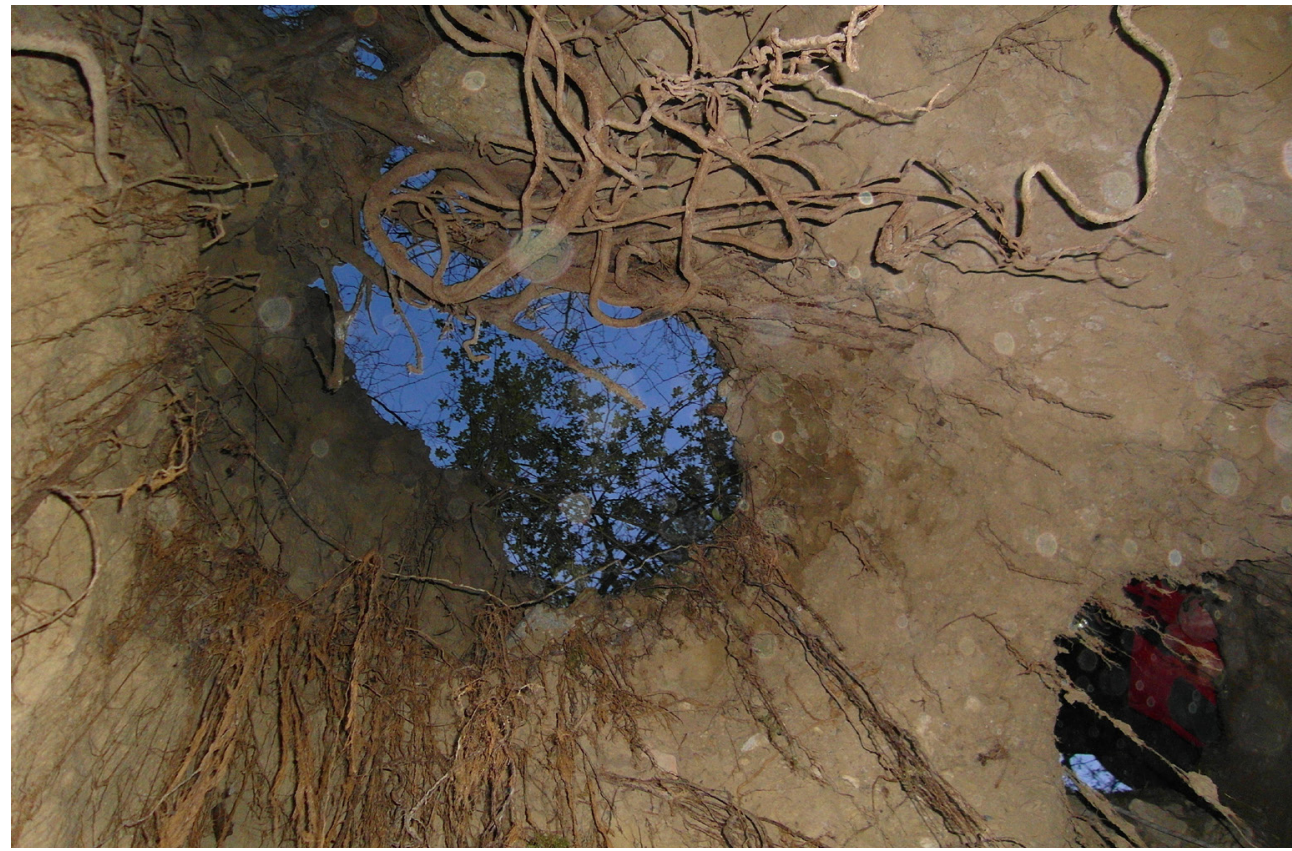

Fig. 9. Partly collapsed chamber in a loess cave near Engelmannsbrunn (Lower Austria, photo June 2011).

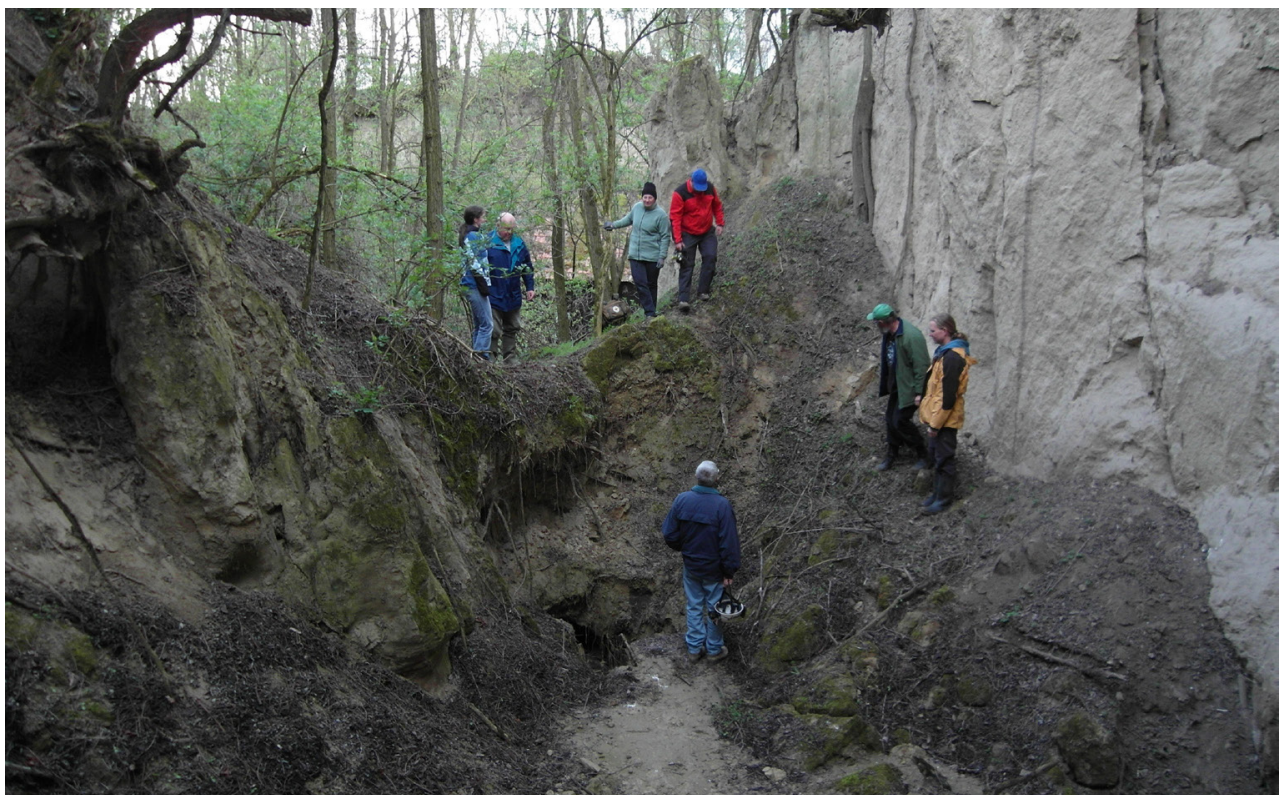

Fig.10. Collapsed loess cave near Engelsmannsbrunn (Lower Austria, photo June 2011). 


\section{OUTLOOK FOR LOESS CAVE} RESEARCH IN AUSTRIA

Besides a certain lack of more extensive field investigations some more or less crucial questions remain as thinkable future research topic:

Are there loess areas favouring the formations of caves?

Are there hydrogeological limitations of the lateral extension of the caves?

Is there any effect of the $\mathrm{CaCO} 3$-content on the formation of the caves?

Can the dissolution of $\mathrm{CaCO} 3$ be neglected?

How is the general timeframe in relation to climatic parameters?

Are there any paleo-loess-caves/passages?

Do protection measures make sense at all?

Main problem still is a lack of interest in these marginal features being spatially iso- lated from the more spectacular alpine karst areas which attract almost all of the available cave scientists. But loess caves might help to redefine the definition of the terminus "pseudokarst", whose weakness maybe caused in part by perfidious troubles of the karst-definition itself.

\section{REFERENCES}

LUKIČ, T. MARKOVIĆ, S. B., STEVENS, T., VASILJEVIĆ, D. A., MACHELLETT, B., MILOJKOVIĆ, N., BASARIN, B. and OBREHT, I. (2009): The loess "cave" near the village of Surduc an unusual pseudokarst landform in the loess of Vojvodina, Serbia.- Acta Carsologica, 38(2-3):227-235

STRIEBEL, T. (2005): Höhlenbildung in "nicht verkarstungsfähigen" Gesteinen: welche Formen sind Karstformen ? - Laichinger Höhlenfreund, 40(1):31-52. 